\title{
Evaluation of the use of mandelate derivatives to determine the enantiomeric purity and the absolute configuration of secondary cyclohexenols
}

\author{
Ariel M. Sarotti, Pablo L. Pisano, and Silvina C. Pellegrinet* \\ Instituto de Química Rosario (CONICET), Facultad de Ciencias Bioquímicas y Farmacéuticas, \\ Universidad Nacional de Rosario, Suipacha 531, Rosario 2000, Argentina \\ E-mail: pellegrinet@iquir-conicet.gov.ar
}

Dedicated to Professors Manuel González Sierra, Rita H. de Rossi, Julio Podestá and Oscar Giordano for their outstanding contribution to organic chemistry in Argentina

\begin{abstract}
The use of mandelate derivatives to determine the enantiomeric purity and the absolute configuration of isomeric mixtures of bicyclic and monocyclic secondary cyclohexenols was investigated. Synthesis, NMR and conformational analyses of the derivatives were performed and Gauge-Independent Atomic Orbital (GIAO) ${ }^{1} \mathrm{H}$ NMR Boltzmann weighted average chemical shifts were computed. The studied methodology proved to be of practical value for most of the systems under study.
\end{abstract}

Keywords: Mandelate derivatives, enantiomeric purity, absolute configuration, NMR spectroscopy, theoretical calculations

\section{Introduction}

NMR spectroscopy is one of the most useful and widely used methods for the determination of the optical purity and the absolute configuration of enantiomerically pure compounds. ${ }^{1}$ The methodology relies on the derivatization of the studied compound with a chiral derivatizing agent (CDA) and comparison of the chemical shifts of the resulting diastereoisomers. The mandelate derivatives of secondary alcohols can be conveniently prepared from the readily available $O$-substituted mandelic acids. ${ }^{2}$ In particular, the use of $O$-acetyl analogues has been shown to be straightforward and give reliable results. ${ }^{2 \mathrm{~d}}$

Our interest in the development of asymmetric Diels-Alder reactions of boron-activated dienophiles has led us to examine the properties of the mandelate derivatives of different bicyclic and monocyclic secondary cyclohexenol products. ${ }^{3}$ Cyclohexenols are versatile building blocks 
for the synthesis of natural and pharmaceutical products. In a previous communication we reported that ${ }^{1} \mathrm{H}$ NMR spectroscopy of the $O$-acetylmandelate and mandelate derivatives could be efficiently used to determine the optical purity and to predict the absolute configuration of endo- and exo-norborn-5-en-2-ol 1, both as a mixture and also as separate diastereomers. ${ }^{4}$ The signals of the bridgehead protons attached to $\mathrm{C} 1$ of the four diastereomeric $O$-acetylmandelates 2 were nicely resolved (Scheme 1). In addition, the signals of $\mathrm{C} 3-\mathrm{H}$ were clearly separated, and the same was observed for the olefinic protons attached to C6 for the endo isomer. Subsequent selective hydrolysis of the acetate group gave the mixture of mandelates 3 without apparent epimerization. The spectra of the mandelates showed $\Delta \delta \mathrm{s}\left(\Delta \delta=\delta_{R}-\delta_{S}\right)$ even higher than those for the $O$-acetylmandelate analogues (Scheme 1). The conformational properties of these derivatives were analyzed using theoretical methods, showing that all major conformers were synperiplanar, as anticipated by the empirical model proposed for secondary $O$ methylmandelates. The methodology was finally validated by computing GIAO ${ }^{1} \mathrm{H}$ NMR Boltzmann weighted average chemical shifts, which were in good agreement with the experimental $\delta$ and $\Delta \delta$ values.

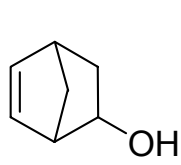

$( \pm)-1$

endo/exo

$75: 25$

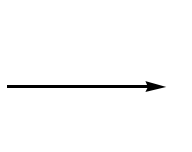

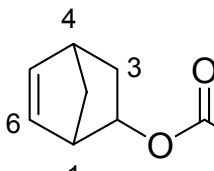

1

$$
\left(\begin{array}{l}
R=A c(2) \\
R=H(3)
\end{array}\right.
$$

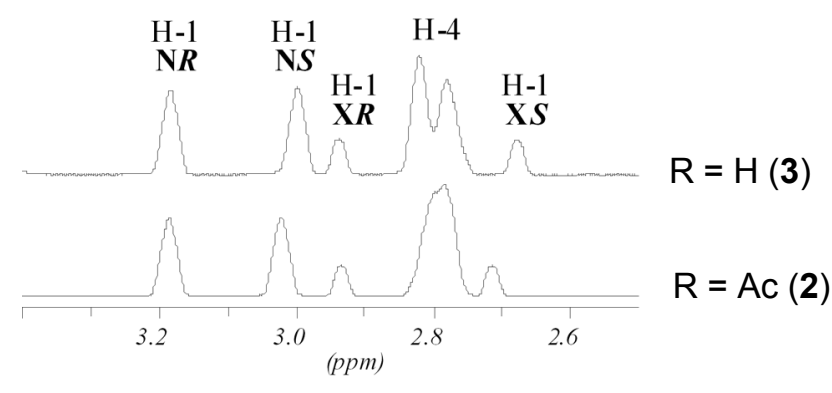

\section{Scheme 1}

As an extension of our previous work, in this paper we wish to report the results of the application of this experimental/theoretical protocol to determine the enantiomeric ratios and to predict the absolute configuration of other bicyclic and monocyclic secondary cyclohexenols. ${ }^{5}$

\section{Results and Discussion}

\section{Synthesis of mandelate derivatives and NMR analysis}

(a) Bicyclo[2.2.2] oct-5-en-2-ol. We first studied the synthesis and use of the $O$-acetylmandelates of endo- and exo-bicyclo[2.2.2] oct-5-en-2-ol 4. Reaction of racemic bicyclo[2.2.2]oct-5-en-2-ol (endo/exo 73:27) with (S)-O-acetylmandelic acid, ${ }^{6} N, N^{\prime}$-dicyclohexylcarbodiimide (DCC) and catalytic 4-(dimethylamino)pyridine (DMAP) in dichloromethane (DCM) gave a mixture of diastereomeric $O$-acetylmandelates 5 in $70 \%$ yield (Scheme 2 ). ${ }^{7}$ Integration of the ${ }^{1} \mathrm{H}$ NMR 
spectrum indicated that the 73:27 endo/exo and 50:50 R/S ratios were maintained. We were disappointed to note that none of the signals of the four diastereoisomers of $O$-acetylmandelates 5 were well resolved in the ${ }^{1} \mathrm{H}$ NMR spectrum. Therefore, $O$-acetylmandelates derivatives were found to be unsuitable to quantify the molar fraction of each compound in the mixture. Subsequent selective hydrolysis of the acetate group with potassium carbonate gave the diastereoisomeric mixture of mandelates 6 without noticeable epimerization. Fortunately, in this case the signals of the bridgehead protons attached to $\mathrm{C} 1$ for the $6 \mathrm{~N} \boldsymbol{R}$ and $\mathbf{6 X} \boldsymbol{R}$ diastereoisomers were baseline resolved (Scheme 2). In addition, the signal of the C6-H corresponding to $6 \mathbf{N S}$ was clearly separated. Finally, the molar fraction of compound $\mathbf{6 X S}$ could be computed by subtracting the integral of the $\mathrm{C} 1-\mathrm{H}$ signal of $\mathbf{6 X} \boldsymbol{R}(2.79-2.72 \mathrm{ppm})$ to the value corresponding to the protons attached to $\mathrm{C} 2$ of both exo diastereoisomers (4.80-4.68 ppm). Alternatively, the signal appearing at $5.20-5.13 \mathrm{ppm}$ for $\mathrm{C}-10 \mathrm{H}$ of $\mathbf{6 X} \boldsymbol{R}$ and $\mathbf{6 X S}$ could be used.

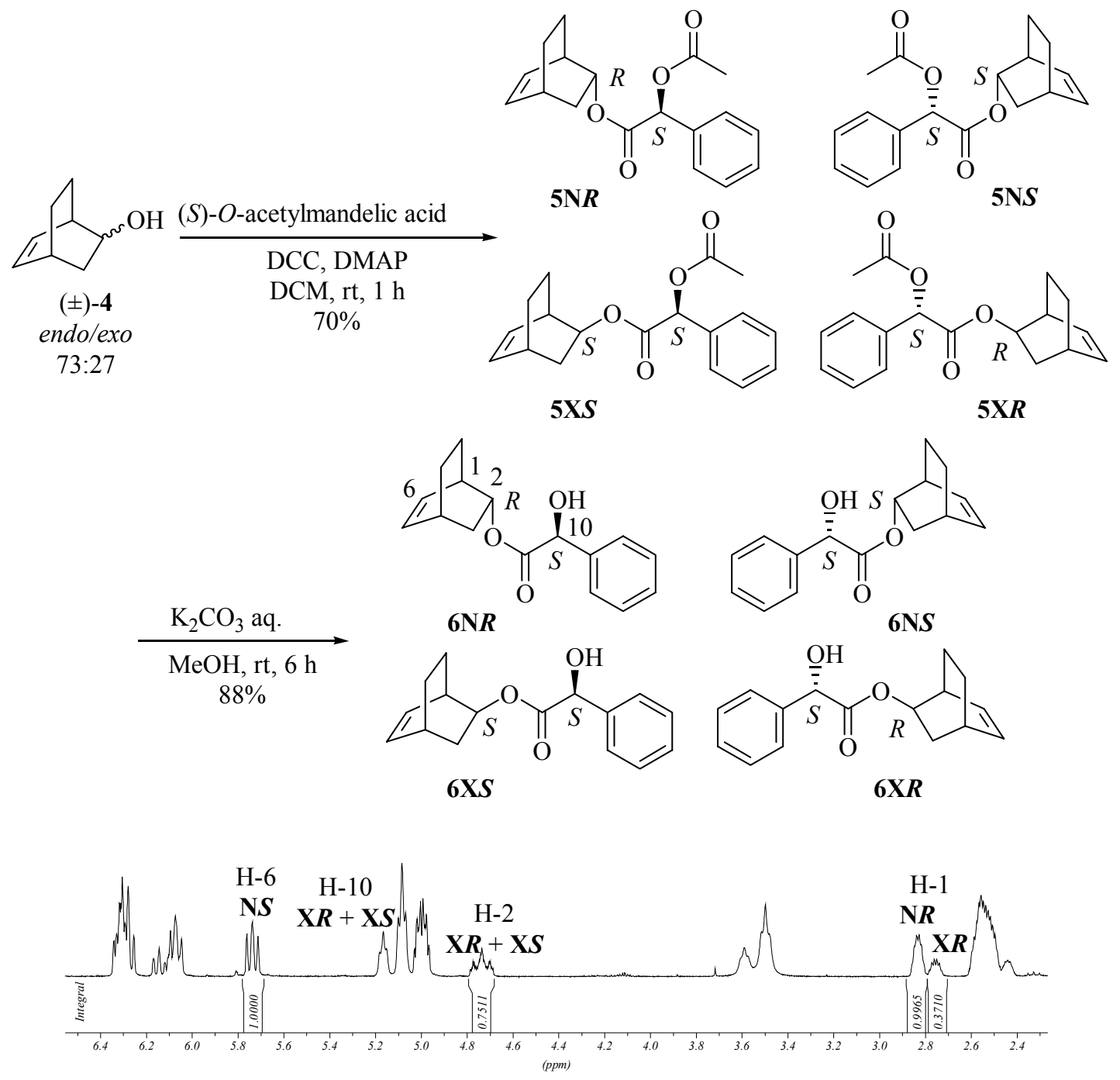

\section{Scheme 2}


(b) 2,5-Diphenyl-cyclohex-3-en-1-ol. We then applied the same methodology to monocylic cyclohexenol 2,5-diphenyl-cyclohex-3-en-1-ol (endo/exo 47:53) 7. The diastereoisomeric mixture of $O$-acetylmandelates $\mathbf{8}$ was quantitatively prepared using standard conditions (Scheme 3). Analysis of the ${ }^{1} \mathrm{H}$ NMR spectra showed that the C2-H signals of $\mathbf{8 N R}$ and $\mathbf{8 X S}$ and the $\mathrm{C} 5-\mathrm{H}$ signal corresponding to $\mathbf{8 X} \boldsymbol{R}$ were all well resolved. The molar fraction of diastereoisomer $\mathbf{8 N} \boldsymbol{S}$ could be computed by subtracting the integral value corresponding to the $\mathrm{C} 2-\mathrm{H}$ signal of $\mathbf{8 N} \boldsymbol{R}$ (3.99-3.91) to the integral value corresponding to the protons attached to $\mathrm{C} 1$ for both endo isomers (5.46-5.26 ppm). Attempts to conduct the partial hydrolysis of $O$-acetylmandelates 8 to the mandelates using potassium carbonate were unsuccessful.<smiles>OC1CC(c2ccccc2)C=CC1c1ccccc1</smiles>

(S)-O-acetylmandelic acid

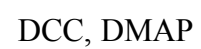

DCM, rt, 1 h $100 \%$

$( \pm)-7$

endo/exo

47:53<smiles>c1ccccc1</smiles>

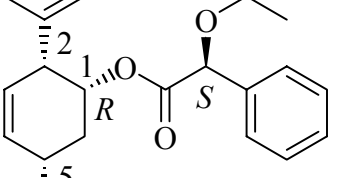<smiles>[CH]1C[AsH]1</smiles><smiles>[C+]1=CC=CC=C1</smiles>

8NR<smiles>c1ccccc1</smiles><smiles>C=C(C)[C@H]1C=C[C@@H](c2ccccc2)C[C@H]1OC(=O)C(=O)O[C@H](C(=O)O)c1ccccc1</smiles>

8XS<smiles>CC(=O)O[C@@H](C(=O)O[C@H]1C[C@H](c2ccccc2)C=C[C@H]1c1ccccc1)c1ccccc1</smiles>

8NS<smiles>[R10][R]</smiles>

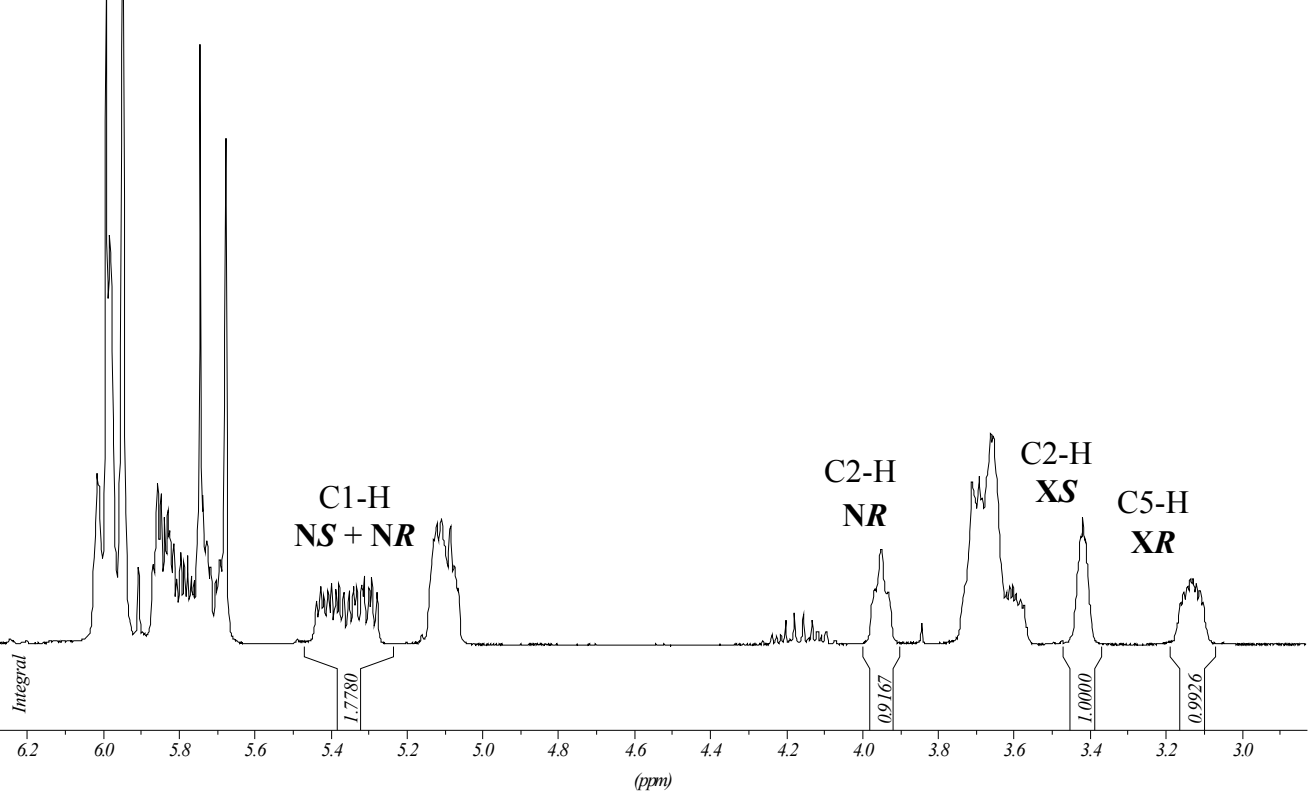

\section{Scheme 3}


(c) 3- and 4-Methyl-3-cyclohexen-1-ol. Finally, we synthesized the $O$-acetylmandelates of a 34:66 mixture of regiosiomers 3- and 4-methyl-3-cyclohexen-1-ol 9 with 93\% yield (Scheme 4). However, only the ratio of the major para isomers could be quantified in the mixture. The $\mathrm{C} 3-\mathrm{H}$ signals in the ${ }^{1} \mathrm{H}$ NMR spectrum were well resolved for 10PR and 10PS (5.28-5.20 ppm and 5.20-5.12 ppm respectively). To our regret, use of the mandelates obtained after partial hydrolysis of mixture $\mathbf{1 0}$ proved unsuccessful too since none of the signals of the corresponding four isomers were well resolved.

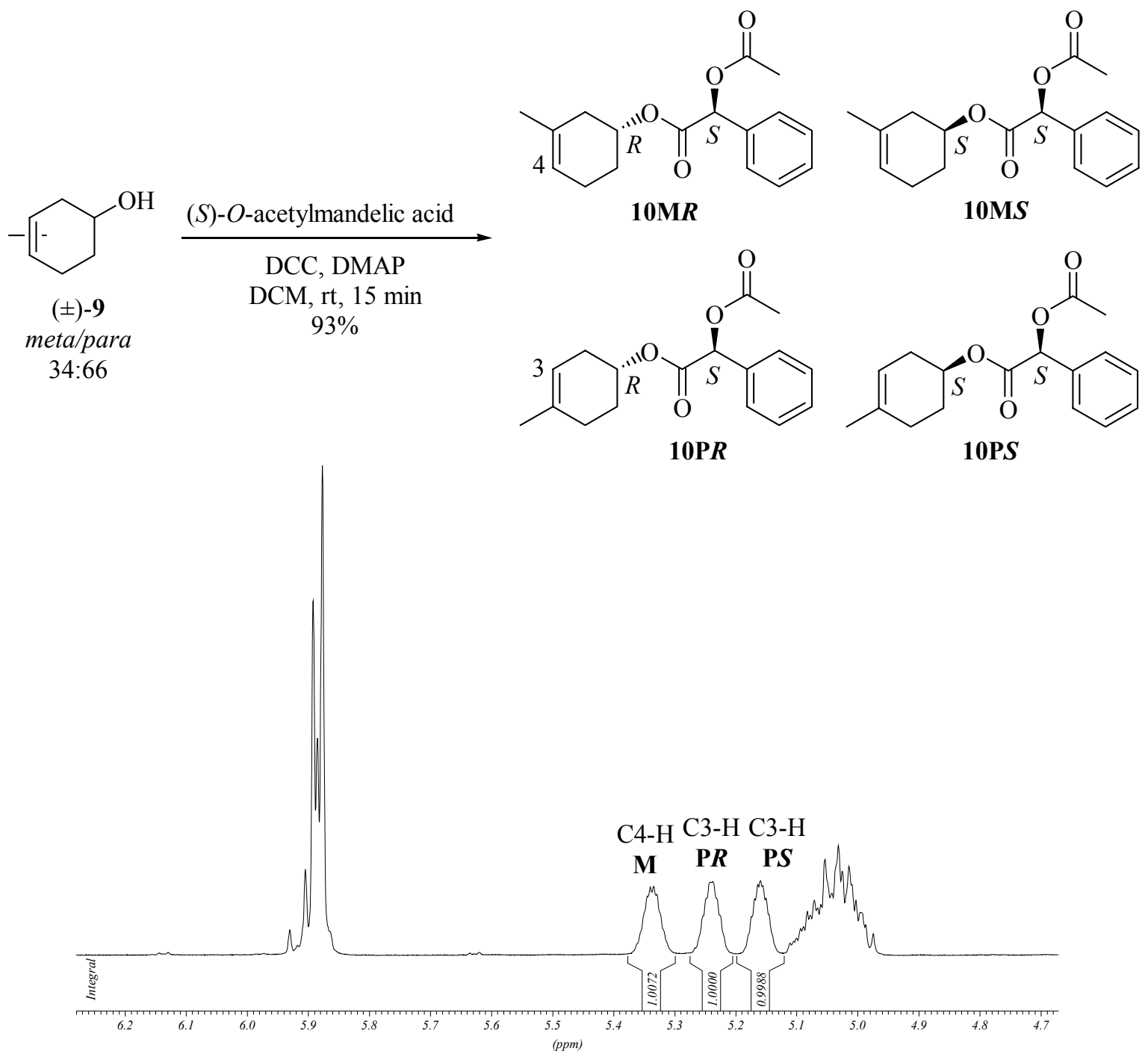

\section{Scheme 4}

\section{Theoretical calculations: conformational analysis and GIAO NMR calculations}

To validate these experiments, we performed theoretical DFT calculations as done in our previous study for the mandelate analogues of endo- and exo-norborn-5-en-2-ol 1. ${ }^{4}$ 
Conformational searches were run to locate the minimum energy conformers of the studied derivatives. Initially, a large number of geometries were generated using the conformational search module of Hyperchem ${ }^{8}$ with the MM+ method. Selected structures were then successively reoptimized at the RHF/AM1, RHF/3-21G and B3LYP/6-31G* levels of theory using Gaussian 03. ${ }^{9}$ Normal coordinate analyses were carried out to confirm the nature of the stationary points and to evaluate the thermochemical properties at $1 \mathrm{~atm}$ and $298.15 \mathrm{~K}$ including zero-point energies (ZPEs) without scaling. Finally, GIAO NMR calculations at the B3LYP/6-31G* level of theory were performed for all significantly populated conformers of each diastereoisomer. The calculated Boltzmann weighted average ${ }^{1} \mathrm{H}$ NMR chemical shifts obtained using relative free energies and TMS as standard were then compared with the experimental values. ${ }^{10}$

(a) Bicyclo[2.2.2]oct-5-en-2-ol. Figure 1 depicts the optimized geometries of the major conformers for mandelates 6, derived from endo- and exo-bicyclo[2.2.2]oct-5-en-2-ol (for all conformers, see the Supplementary Material). In agreement with the empirical model, ${ }^{2 a, 2 c}$ all global minima correspond to conformations in which the carbinolic proton, the carbonyl oxygen and hydroxy group are synperiplanar. ${ }^{11}$ This is in good agreement with our previous results for the derivatives of norborn-5-en-2-ol (1). ${ }^{4}$ For each compound, we found two synperiplanar conformers of similar energies, having H-C2-O-C9 torsion angles $(\varphi)$ of $c a .40^{\circ}$ and $-40^{\circ}$. In some cases, antiperiplanar conformations were also located, but the relative energies of these structures were much higher so that they do not contribute to the population. Consequently, they were not considered in the GIAO NMR calculation. As expected, all structures showed a H-bond interaction between the free hydroxy group of the mandelate and the carbonyl oxygen.

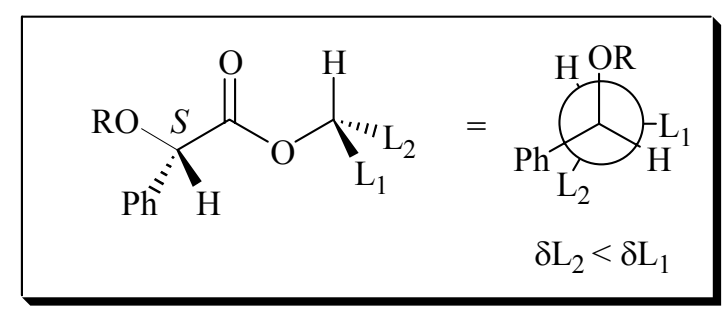

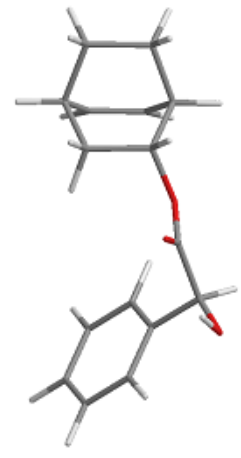

6NR

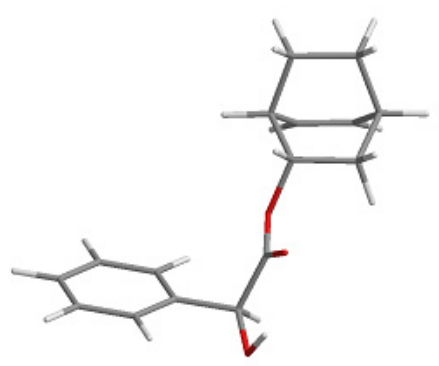

6NS

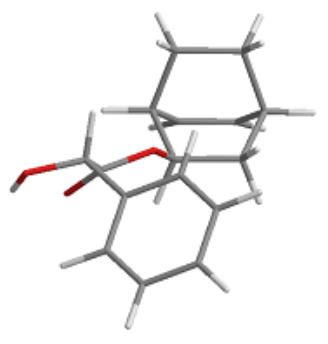

6XR

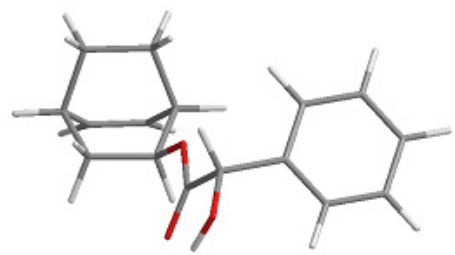

6XS

Figure 1 
The Boltzmann weighted average ${ }^{1} \mathrm{H}$ NMR chemical shifts were computed using both synperiplanar conformers for each compound and are gathered in Table 1, together with the corresponding experimental values. As can be seen, the calculated and experimental $\delta$ and $\Delta \delta$ values correlate very well. ${ }^{12}$ The most interesting results arise from the shielding of H-6 for 6NS and the deshielding of $\mathrm{H}-1$ for the endo and exo diastereosiomers having the $R$ absolute configuration at the carbinolic proton $(\mathbf{6 N} \boldsymbol{R}$ and $\mathbf{6 X} \boldsymbol{R})$ relative to their diastereoisomer having the opposite configuration, which is correctly predicted by the calculations. The simple observation of the molecular models in Figure 1 evidences the greater spatial proximity of the phenyl ring to $\mathrm{H}-1$ in the $\mathbf{6 N} \boldsymbol{S}$ and $\mathbf{6 X S}$ counterparts and also to H-6 in $\mathbf{6 N S}$. Although the endo and exo protons attached to $\mathrm{C}-3$ are affected by the anisotropy generated by the aromatic ring too, the corresponding signals appear in a complex region of the NMR spectrum and are overlapped by the signals of H-7 and H-8 so they cannot be used for the purpose of this study.

Table 1. Experimental and calculated ${ }^{1} \mathrm{H}$ NMR $\delta$ and $\Delta \delta$ values (in ppm) for selected nuclei of mandelates $6^{\mathrm{a}}$

\begin{tabular}{|c|c|c|c|c|c|c|c|c|c|}
\hline & & \multicolumn{2}{|c|}{ H-1 } & \multicolumn{2}{|c|}{$\mathrm{H}-3 \mathrm{n}$} & \multicolumn{2}{|c|}{ H-3x } & \multicolumn{2}{|c|}{ H-6 } \\
\hline & & Exp. & Calcd. & Exp. & Calcd. & Exp. & Calcd. & Exp. & Calcd. \\
\hline \multirow{3}{*}{$6 \mathrm{~N}$} & $\delta_{R}$ & 2.83 & 2.86 & 0.93 & 1.17 & 1.88 & 1.88 & 6.07 & 6.40 \\
\hline & $\delta_{S}$ & 2.54 & 2.56 & 1.27 & 1.45 & 2.02 & 2.12 & 5.74 & 6.16 \\
\hline & $\Delta \delta_{R S}$ & 0.29 & 0.29 & -0.34 & -0.28 & -0.14 & -0.25 & 0.33 & 0.24 \\
\hline \multirow{3}{*}{$6 X$} & $\delta_{R}$ & 2.76 & 2.79 & 1.74 & 1.71 & 0.86 & 1.13 & 6.15 & 6.25 \\
\hline & $\delta_{S}$ & 2.54 & 2.54 & 1.85 & 1.95 & 1.27 & 1.41 & 6.08 & 6.17 \\
\hline & $\Delta \delta_{R S}$ & 0.22 & 0.25 & -0.11 & -0.24 & -0.41 & -0.28 & 0.07 & 0.07 \\
\hline
\end{tabular}

${ }^{\mathrm{a}} \Delta \delta=\delta_{R}-\delta_{S}$

(b) 2,5-Diphenyl-cyclohex-3-en-1-ol. The global minima for $O$-acetylmandelates of both diastereoisomers of 2,5-diphenyl-cyclohex-3-en-1-ol 8 are shown in Figure 2 (for all conformers, see the Supplementary Material). Again, they all have a synperiplanar arrangement of the carbinolic proton, the carbonyl and the oxygen of acetate group, as expected from the empirical model. ${ }^{2 a, 2 \mathrm{c}}$ However, contrary to the mandelates of bicyclo[2.2.2] oct-5-en-2-ol 6, in this case only one synperiplanar conformation was found for each compound. In addition, conformations with antiperiplanar arrangements of the carbonyl of the mandelate and the oxygen of the acetate contributed to the population of $O$-acetylmandelates 8 to different extents (up to $32 \%$ ). For instance, two antiperiplanar conformations of similar energy that represent $21 \%$ and $11 \%$ of the population were located for $\mathbf{8 X S}$. As has been previously observed for other systems, ${ }^{4}$ this corroborates that $O$-acetylmandelates are more flexible than mandelates, which are locked in synperiplanar conformations by the H-bond interaction between the carbonyl oxygen and the free hydroxyl group. It is interesting to note that the $O$-acetylmandelate substituent adopts a pseudoequatorial position in the endo isomers, while it occupies a pseudo-axial position in the exo 
analogues. This might have consequences on the success of the application of the proposed methodology, since the phenyl group of the $O$-acetylmandelate moiety is correctly positioned to influence the chemical shifts of other nuclei in the cyclohexene ring in exo structures, while in their endo counterparts it might be too far away. ${ }^{13}$

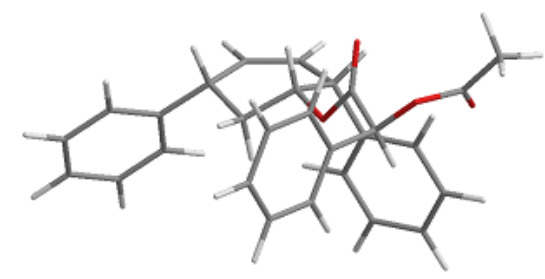

$\mathbf{8 N R}$

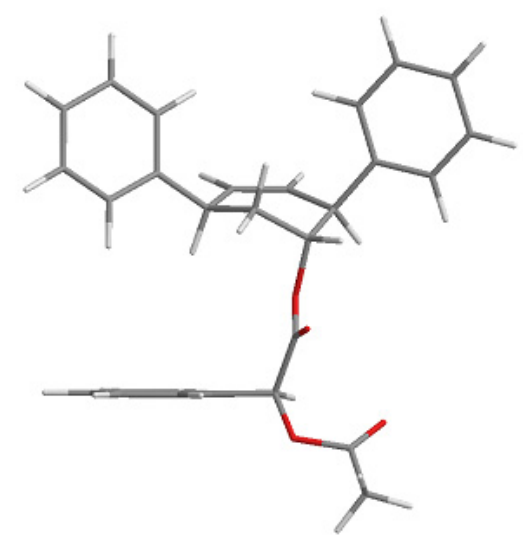

$\mathbf{8 X R}$

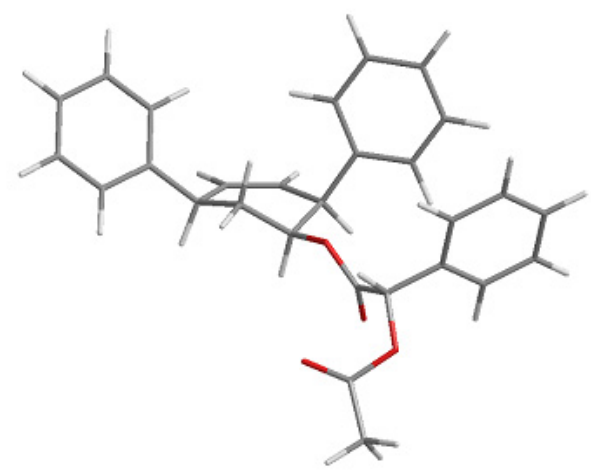

8NS

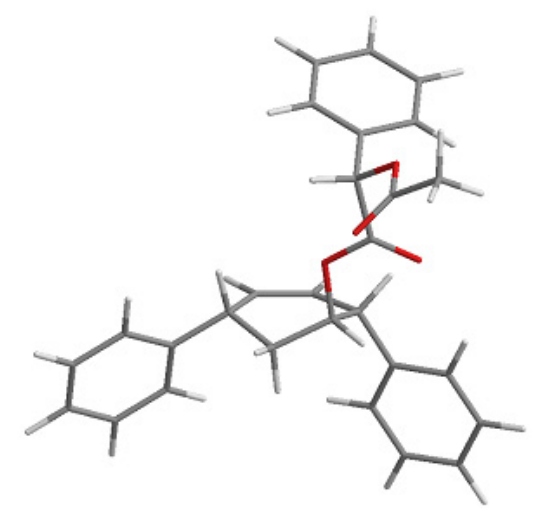

8XS

\section{Figure 2}

Since antiperiplanar conformations are significant for $O$-acetylmandelates $\mathbf{8}$, they had to be considered for computing the Boltzmann weighted average ${ }^{1} \mathrm{H}$ NMR chemical shifts. Gratifyingly, the experimental $\delta$ and $\Delta \delta$ values were correctly reproduced, as can be observed from Table 2. ${ }^{12}$ In this case, the shielding of H-5 in $\mathbf{8 X R}$ and of H-2 in $\mathbf{8 X S}$ suggested by the models depicted in Figure 2 is correctly predicted by the calculations. Unfortunately, the signals of the olefinic hydrogens attached to $\mathrm{C}-3$ are overlapped with those for $\mathrm{H}-4$ and $\mathrm{H}-8$, while all $\mathrm{C}$ 6 methylenes appear in the same region of the spectrum. 
Table 2. Experimental and calculated ${ }^{1} \mathrm{H}$ NMR $\delta$ and $\Delta \delta$ values (in ppm) for selected nuclei of $O$-acetylmandelates $\mathbf{8}^{\mathrm{a}}$

\begin{tabular}{cccccccccccc}
\hline & & \multicolumn{2}{c}{$\mathrm{H}-2$} & \multicolumn{2}{c}{$\mathrm{H}-3$} & \multicolumn{2}{c}{$\mathrm{H}-5$} & \multicolumn{2}{c}{$\mathrm{H}-6_{\text {syn }}$} & \multicolumn{2}{c}{$\mathrm{H}-6_{\text {anti }}$} \\
& & Exp. & Calcd. & Exp. & Calcd. & Exp. & Calcd. & Exp. & Calcd. & Exp. & Calcd. \\
\hline \multirow{4}{*}{$\mathbf{8 N}$} & $\delta_{R}$ & 3.95 & 3.90 & 5.84 & 6.02 & 3.60 & 3.40 & 1.73 & 1.68 & 1.64 & 1.19 \\
& $\delta_{S}$ & 3.72 & 3.88 & 5.77 & 5.91 & 3.69 & 3.56 & 2.03 & 1.88 & 1.86 & 1.73 \\
& $\boldsymbol{\Delta} \delta_{\boldsymbol{R} S}$ & $\mathbf{0 . 2 3}$ & $\mathbf{0 . 0 2}$ & $\mathbf{0 . 0 7}$ & $\mathbf{0 . 1 2}$ & $\mathbf{- 0 . 0 9}$ & $\mathbf{- 0 . 1 5}$ & $\mathbf{- 0 . 3 0}$ & $\mathbf{- 0 . 2 0}$ & $\mathbf{- 0 . 2 2}$ & $\mathbf{- 0 . 5 4}$ \\
$\mathbf{8 X}$ & $\delta_{R}$ & 3.65 & 3.63 & 6.00 & 5.94 & 3.13 & 2.70 & 1.83 & 1.70 & 1.64 & 1.38 \\
& $\delta_{S}$ & 3.42 & 3.47 & 5.71 & 5.76 & 3.69 & 3.63 & 2.11 & 1.78 & 1.83 & 1.57 \\
& $\boldsymbol{\Delta} \boldsymbol{\delta}_{\boldsymbol{R} S}$ & $\mathbf{0 . 2 3}$ & $\mathbf{0 . 1 5}$ & $\mathbf{0 . 2 9}$ & $\mathbf{0 . 1 8}$ & $\mathbf{- 0 . 5 6}$ & $\mathbf{- 0 . 9 3}$ & $\mathbf{- 0 . 2 8}$ & $\mathbf{- 0 . 0 8}$ & $\mathbf{- 0 . 1 9}$ & $\mathbf{- 0 . 2 0}$ \\
\hline
\end{tabular}

${ }^{\mathrm{a}} \Delta \delta=\delta_{R}-\delta_{S}{ }^{\mathrm{b}}$ Syn and anti are relative to the $O$-acetylmandelate group in C-1.

(c) 3- and 4-Methyl-3-cyclohexen-1-ol. Figure 3 shows the optimized geometries of the major conformers of regioisomeric $O$-acetylmandelates 10-M and 10-P, respectively derived from 3and 4-methyl-3-cyclohexen-1-ol (for all conformers, see the Supplementary Material). Once more, in all global minima the carbinolic proton and the carbonyl and acetate oxygens are synperiplanar. ${ }^{11}$ In this case, two synperiplanar conformations of similar energy were found for each compound, with $\mathrm{H}-\mathrm{C} 1-\mathrm{O}-\mathrm{C} 8$ torsion angles $(\varphi)$ of approximately $35^{\circ}$ and $-35^{\circ}$, in which the $O$-acetylmandelate groups occupy pseudo-equatorial positions. These conformations account for ca. $65 \%$ of the population.

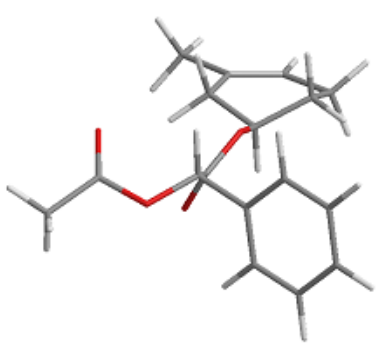

$10 \mathrm{M} R$

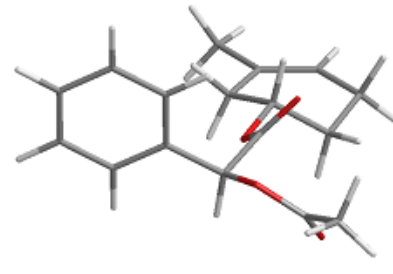

$10 \mathrm{MS}$

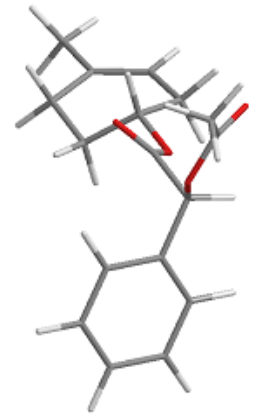

10PR

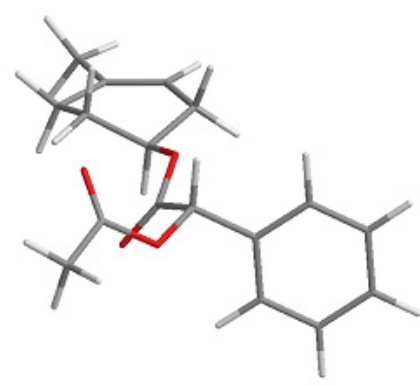

10PS

\section{Figure 3}

In addition, the synperiplanar conformations with pseudo-axial $O$-acetylmandelate groups represent around $30 \%$ of the population for each system. Again, the phenyl is better located to shield other nuclei in the cyclohexene ring in conformations where the $O$-acetylmandelate group occupies a pseudo-axial position. For these regioisomeric systems both diastereoisomers have contributing structures of this type. Antiperiplanar conformations were located too, but their 
contribution to the population is relatively small (less than 10\%). These results reinforce the idea that $O$-acetylmandelates can adopt more conformations than H-bond locked mandelates. ${ }^{4}$

All conformations that contribute more than $5 \%$ to the Boltzmann distribution were considered to calculate the GIAO ${ }^{1} \mathrm{H}$ NMR chemical shifts. Key experimental and calculated chemical shifts shown in Table 3 indicate that the correlation is very good. ${ }^{12}$ However, only the signals of olefinic protons of the para isomer $(\mathrm{H}-3$ of 10P) were of practical value since the ones corresponding to the meta analogue (H-4 of 10M) superimpose and all the other signals appear in a very narrow region of the spectrum centered around $2 \mathrm{ppm}$. These results indicate that this methodology cannot be used to determine the optical purity of 3-methyl-3-cyclohexen-1-ol, at least when forming part of a regioisomeric mixture with 4-methyl-3-cyclohexen-1-ol.

Table 3. Experimental and calculated ${ }^{1} \mathrm{H}$ NMR $\delta$ and $\Delta \delta$ values (in ppm) for selected nuclei of $O$-acetylmandelates $\mathbf{1 0}^{\text {a }}$

\begin{tabular}{|c|c|c|c|c|c|c|c|c|c|}
\hline & & \multicolumn{2}{|c|}{ H-4 } & \multicolumn{2}{|c|}{$\mathrm{H}-2_{\text {syn }}$} & \multicolumn{2}{|c|}{$\mathrm{H}-6_{s v n}$} & \multicolumn{2}{|c|}{$\mathrm{H}-6_{\text {anti }}$} \\
\hline & & Exp. & Calcd. & Exp. & Calcd. & Exp. & Calcd. & Exp. & Calcd. \\
\hline \multirow{5}{*}{$10 \mathrm{M}$} & $\delta_{R}$ & 5.34 & 5.34 & 2.05 & 2.10 & 1.91 & 1.39 & 1.91 & 1.43 \\
\hline & $\delta_{S}$ & 5.34 & 5.40 & 1.83 & 1.91 & 2.10 & 1.72 & 2.10 & 1.73 \\
\hline & $\Delta \delta_{R S}$ & 0.00 & -0.06 & .22 & 0.19 & -0.19 & -0.33 & -0.19 & -0.31 \\
\hline & & \multicolumn{2}{|c|}{$\mathrm{H}-3$} & \multicolumn{2}{|c|}{$\mathrm{H}-2_{\text {syn }}$} & \multicolumn{2}{|c|}{$\mathrm{H}-6_{s y n}$} & \multicolumn{2}{|c|}{$\mathrm{H}-6_{\text {anti }}$} \\
\hline & $\delta_{R}$ & $\begin{array}{l}\text { Exp. } \\
5.24\end{array}$ & $\begin{array}{c}\text { Calcd. } \\
5.35\end{array}$ & $\begin{array}{l}\text { Exp. } \\
2.04\end{array}$ & $\begin{array}{c}\text { Calcd. } \\
2.07\end{array}$ & $\begin{array}{l}\text { Exp. } \\
2.19\end{array}$ & $\begin{array}{c}\text { Calcd. } \\
1.56\end{array}$ & $\begin{array}{l}\text { Exp. } \\
1.90\end{array}$ & $\begin{array}{c}\text { Calcd. } \\
1.64\end{array}$ \\
\hline \multirow[t]{2}{*}{ 10P } & $\delta_{S}$ & 5.16 & 5.24 & 1.67 & 1.80 & 2.34 & 1.80 & 2.10 & 2.09 \\
\hline & $\Delta \delta_{R S}$ & 0.08 & 0.11 & 0.37 & 0.27 & -0.15 & -0.23 & -0.20 & -0.44 \\
\hline
\end{tabular}

${ }^{\mathrm{a}} \Delta \delta=\delta_{R}-\delta_{S .}{ }^{\mathrm{b}} S y n$ and anti are relative to the $O$-acetylmandelate group in C-1.

\section{Conclusions}

Synthesis, NMR and conformational analyses of the mandelate derivatives of isomeric mixtures of bicyclic and monocyclic secondary cyclohexenols were performed and GIAO ${ }^{1} \mathrm{H}$ NMR Boltzmann weighted average chemical shifts were computed. Synthesis of $O$-acetylmandelates was trivial for all systems and these compounds were found to be suitable to determine the enantiomeric ratio and the absolute configuration of monocylic cyclohexenols 2,5-diphenylcyclohex-3-en-1-ol (endo/exo 47:53) and 4-methyl-3-cyclohexen-1-ol (meta/para 34:66). The mandelates derived from bicyclo[2.2.2]oct-5-en-2-ol (endo/exo 73:27) were obtained by partial hydrolysis of the acetate group without epimerization and could be successfully used for the studied purpose. The proposed methodology only failed for 3-methyl-3-cyclohexen-1-ol since none of the signals were well resolved. These results, together with those derived from our previous investigations for norborn-5-en-2-ol, suggest that mandelic acids can be used as CDAs 
for bicyclic and monocyclic secondary cyclohexenols with different patterns of substitution. To reach reliable conclusions, it is highly recommended that experimental results are complemented with thorough conformational analyses followed by GIAO NMR calculations.

\section{Experimental Section}

General. All non-aqueous reactions were performed in oven dried glassware under positive argon pressure. All reagents and solvents were used directly as purchased or purified according to standard procedures. DCM was distilled from calcium hydride. Methanol was purchased from Cicarelli in a pro analysis grade and used directly. Analytical thin layer chromatography was carried out using commercial silica gel plates (Merck, Silica Gel 60 F254) and visualization was effected with short wavelength UV light $(254 \mathrm{~nm})$ and a $p$-anisaldehyde solution $(2.5 \mathrm{~mL} p$ anisaldehyde $\left.+2.5 \mathrm{~mL} \mathrm{H}_{2} \mathrm{SO}_{4}+0.25 \mathrm{~mL} \mathrm{AcOH}+95 \mathrm{~mL} \mathrm{EtOH}\right)$. Column chromatography was performed with silica gel $60 \mathrm{H}$ (Merck), slurry packed, run under nitrogen pressure. NMR spectra were recorded at $300 \mathrm{MHz}$ for ${ }^{1} \mathrm{H}$, and $75 \mathrm{MHz}$ for ${ }^{13} \mathrm{C}$ on a Bruker Avance-300 DPX spectrometer with $\mathrm{CDCl}_{3}$ as solvent and $\left(\mathrm{CH}_{3}\right)_{4} \mathrm{Si}\left({ }^{1} \mathrm{H}\right)$ or $\mathrm{CDCl}_{3}\left({ }^{13} \mathrm{C}, 76.9 \mathrm{ppm}\right)$ as internal standards. Chemical shifts are reported in delta $(\delta)$ units in parts per million (ppm) and splitting patterns are designated as s, singlet; d, doublet; t, triplet; q, quartet; m, multiplet and br, broad. Resonances having ambiguous assignments are denoted by asterisks $(*)$, double asterisks $(* *)$ and daggers $\left({ }^{\dagger}\right)$. Diastereoisomeric ratios were determined by ${ }^{1} \mathrm{H}$ NMR analysis. Infrared spectra were recorded on a Shimadzu IR Prestige-21 spectrometer using sodium chloride plates pellets. High resolution mass spectra (HRMS) were obtained at the UCR Mass Spectrometry Facility, Department of Chemistry, University of California.

$\boldsymbol{O}$-Acetylmandelates (5). To a solution of racemic bicyclo[2.2.2]oct-5-en-2-ol (endo/exo 73:27) $(56.2 \mathrm{mg}, 0.45 \mathrm{mmol})$ in dry DCM $(4.8 \mathrm{~mL})$, DMAP (11 mg, $0.09 \mathrm{mmol}),(S)-O$-acetylmandelic acid (176 mg, $0.907 \mathrm{mmol})$ and DCC (187 $\mathrm{mg}, 0.906 \mathrm{mmol})$ were added and the mixture was stirred at room temperature for 60 minutes under argon. The reaction was diluted with DCM and filtered through Celite. The filtrate was concentrated under reduced pressure and purified by column chromatography (hexane/ethyl acetate) to afford a mixture of $O$-acetylmandelates $\mathbf{5}$ as a colorless oil (95.1 mg, 70\%, endo/exo 73:27, 5NR/5NS 50:50 and 5XR/5XS 50:50). IR (film) $v_{\max }: 3048,2949,2868,1742,1373,1271,1233,1211,1178,1090,1057,1009,696 \mathrm{~cm}^{-1} .{ }^{1} \mathrm{H}$ NMR (300 MHz; $\left.\mathrm{CDCl}_{3}\right) \delta: 7.51-7.33(\mathrm{~m}, 20 \mathrm{H}, \mathrm{ArH}), 6.36-6.25$ (m, 4H, H-5NS, H-5NR, H$5 \mathrm{XS}$ and $\mathrm{H}-5 \mathrm{X} R), 6.17-6.05(\mathrm{~m}, 3 \mathrm{H}, \mathrm{H}-6 \mathrm{~N} R, \mathrm{H}-6 \mathrm{X} R$ and $\mathrm{H}-6 \mathrm{XS}), 5.92(\mathrm{~s}, 1 \mathrm{H}, \mathrm{H}-10 \mathrm{X} R)^{\dagger}, 5.92$ (s, 1H, H-10XS) ${ }^{\dagger}, 5.83-5.76$ (m, 3H, H-6NS, H-10NS and H-10NR), 5.00-4.93 (m, 2H, H-2NS and $\mathrm{H}-2 \mathrm{~N} R), 4.75-4.65(\mathrm{~m}, 2 \mathrm{H}, \mathrm{H}-2 \mathrm{XS}$ and $\mathrm{H}-2 \mathrm{X} R), 2.86-2.79(\mathrm{~m}, 1 \mathrm{H}, \mathrm{H}-1 \mathrm{~N} R), 2.79-2.74(\mathrm{~m}$, $1 \mathrm{H}, \mathrm{H}-1 \mathrm{X} R$ ), 2.63-2.44 (m, 6H, H-1NS, H-1XS, H-4N $S, \mathrm{H}-4 \mathrm{~N} R, \mathrm{H}-4 \mathrm{XS}$ and $\mathrm{H}-4 \mathrm{X} R$ ), 2.21 (s, $3 \mathrm{H}, \mathrm{H}-12 \mathrm{X} R)^{*}, 2.20(\mathrm{~s}, 3 \mathrm{H}, \mathrm{H}-12 \mathrm{XS}) *, 2.18(\mathrm{~s}, 6 \mathrm{H}, \mathrm{H}-12 \mathrm{~N} S$ and $\mathrm{H}-12 \mathrm{~N} R), 2.04-1.83(\mathrm{~m}, 4 \mathrm{H}, \mathrm{H}-$ $3 \mathrm{xN} S, \mathrm{H}-3 \mathrm{xN} R, \mathrm{H}-7 \mathrm{aX} R$ and $\mathrm{H}-7 \mathrm{aXS}), 1.83-1.71(\mathrm{~m}, 2 \mathrm{H}, \mathrm{H}-3 \mathrm{nX} R$ and $\mathrm{H}-3 \mathrm{nXS}), 1.56-1.07$ (m, 
$15 \mathrm{H}, \mathrm{H}-7 \mathrm{bX} R^{* *}, \mathrm{H}-3 \mathrm{x} X S, \mathrm{H}-8 \mathrm{aX} R, \mathrm{H}-8 \mathrm{aXS}, \mathrm{H}-8 \mathrm{bX} R, \mathrm{H}-8 \mathrm{bXS}, \mathrm{H}-3 \mathrm{nN} S, \mathrm{H}-8 \mathrm{aN} R, \mathrm{H}-8 \mathrm{aN} S, \mathrm{H}-$ $8 \mathrm{bN} R, \mathrm{H}-8 \mathrm{bN} S, \mathrm{H}-7 \mathrm{aN} R, \mathrm{H}-7 \mathrm{aN} S, \mathrm{H}-7 \mathrm{bN} R$ and $\mathrm{H}-7 \mathrm{bN} S), 1.03-0.81(\mathrm{~m}, 3 \mathrm{H}, \mathrm{H}-3 \mathrm{nN} R, \mathrm{H}-3 \mathrm{xX} R$ and $\left.\mathrm{H}-7 \mathrm{bXS} S^{* *}\right) .{ }^{13} \mathrm{C}$ NMR $\left(75 \mathrm{MHz} ; \mathrm{CDCl}_{3}\right) \delta: 170.3$ (4 C, C-11N and C-11X), $168.5(2 \mathrm{C}, \mathrm{C}-$ 9X), 168.4 (2 C, C-9N), 136.2 (2 CH, C-5X), 135.0 (2 CH, C-5N), 134.0 (C, ArX), 133.8 (2 C, ArX and ArN), 133.6 (C, ArN), 130.7 (2 CH, C-6X), 129.7 (CH, C-6NR), 129.6 (CH, C-6NS), 129.0 and $128.9(4 \mathrm{CH}, \operatorname{ArX}$ and $\mathrm{ArN}), 128.6$ and $128.5(8 \mathrm{CH}, \operatorname{ArX}$ and $\mathrm{ArN}), 127.5,127.4$ and 127.3 (8 CH, ArX and ArN), 74.8 (2 CH, C-2N), $74.7(\mathrm{CH}, \mathrm{C}-10 \mathrm{X}), 74.6(2 \mathrm{CH}, \mathrm{C}-10 \mathrm{~N}), 74.6$ (CH, C-10X), $73.6(2 \mathrm{CH}, \mathrm{C}-2 \mathrm{X}), 35.2\left(2 \mathrm{CH}_{2}, \mathrm{C}-3 \mathrm{~N}\right), 33.7(\mathrm{CH}, \mathrm{C}-1 \mathrm{X}), 33.6(2 \mathrm{CH}, 2 \mathrm{C}, \mathrm{C}-1 \mathrm{X}$ and $\mathrm{C}-1 \mathrm{~N}), 33.5(\mathrm{CH}, \mathrm{C}-1 \mathrm{~N}), 33.0\left(\mathrm{CH}_{2}, \mathrm{C}-3 \mathrm{X}\right), 32.8\left(\mathrm{CH}_{2}, \mathrm{C}-3 \mathrm{X}\right), 29.6(\mathrm{CH}, \mathrm{C}-4 \mathrm{X}), 29.4(2$ $\mathrm{CH}, \mathrm{C}-4 \mathrm{~N}), 29.3(\mathrm{CH}, \mathrm{C}-4 \mathrm{X}), 25.0\left(\mathrm{CH}_{2}, \mathrm{C}-8 \mathrm{X}\right), 24.8\left(\mathrm{CH}_{2}, \mathrm{C}-8 \mathrm{X}\right), 23.5\left(2 \mathrm{CH}_{2}, \mathrm{C}-8 \mathrm{~N}\right), 21.5$ $\left(\mathrm{CH}_{2}, \mathrm{C}-7 \mathrm{~N}\right), 21.4\left(\mathrm{CH}_{2}, \mathrm{C}-7 \mathrm{~N}\right), 20.6\left(4 \mathrm{CH}_{3}, \mathrm{C}-12 \mathrm{~N}\right.$ and $\left.\mathrm{C}-12 \mathrm{X}\right), 18.2\left(\mathrm{CH}_{2}, \mathrm{C}-7 \mathrm{X}\right), 17.9\left(\mathrm{CH}_{2}\right.$, C-7X). HRMS calcd for $\mathrm{C}_{18} \mathrm{H}_{24} \mathrm{NO}_{4}\left(\mathrm{M}+\mathrm{NH}_{4}\right)^{+}: 318.1700$, found: 318.1701 .

Mandelates (6). A mixture of the $\mathbf{5}(74.6 \mathrm{mg}, 0.25 \mathrm{mmol}, \mathbf{5 N} / \mathbf{5 X} 73: 27, \mathbf{5 N R} / \mathbf{5 N S} 50: 50$ and

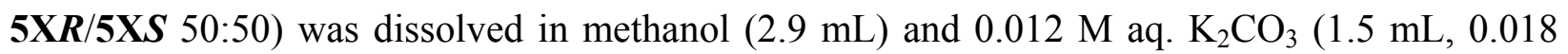
$\mathrm{mmol}$ ) was added. The solution was stirred at room temperature for $6 \mathrm{~h}$. After neutralization with $0.1 \mathrm{~N}$ aq. $\mathrm{HCl}$, the solvent was evaporated under reduced pressure and the crude mixture was purified by column chromatography (hexane/ethyl acetate) to afford a mixture of mandelates $\mathbf{6}$ as a colorless oil (56.5 mg, 88\%, endo/exo 73:27, $\mathbf{6 N R / 6 N S ~ 5 0 : 5 0 ~ a n d ~ 6 X R / 6 X S ~ 5 0 : 5 0 ) . ~ I R ~ ( f i l m ) ~}$ $v_{\max }: 3469,3048,2948,2868,1729,1449,1264,1211,1184,1091,1068,1006,734,698 \mathrm{~cm}^{-1}$.

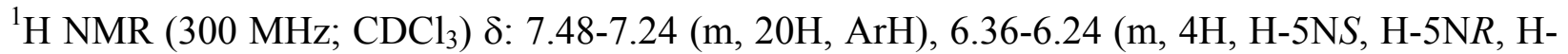
$5 \mathrm{X} R$ and H-5XS), 6.18-6.03 (m, 3H, H-6NR, H-6XR and H-6XS), 5.74 (dd, $J=7.2 \mathrm{~Hz}, J=7.2$ $\mathrm{Hz}, 1 \mathrm{H}, \mathrm{H}-6 \mathrm{~N} S), 5.20-5.13(\mathrm{~m}, 2 \mathrm{H}, \mathrm{H}-10 \mathrm{X} R$ and $\mathrm{H}-10 \mathrm{XS}), 5.12-5.05(\mathrm{~m}, 2 \mathrm{H}, \mathrm{H}-10 \mathrm{~N} R$ and $\mathrm{H}-$ $10 \mathrm{~N} S$ ), 5.04-4.96 (m, $2 \mathrm{H}, \mathrm{H}-2 \mathrm{~N} R$ and $\mathrm{H}-2 \mathrm{~N} S$ ), 4.80-4.68 (m, 2H, H-2XR and H-2XS), 3.63-3.55 $(\mathrm{m}, 2 \mathrm{H}, \mathrm{OH} \mathrm{XR}$ and $\mathrm{OH} \mathrm{XS}), 3.55-3.43(\mathrm{~m}, 2 \mathrm{H}, \mathrm{OH} \mathrm{N} R$ and $\mathrm{OH} \mathrm{N} S), 2.87-2.80(\mathrm{~m}, 1 \mathrm{H}, \mathrm{H}-$ $1 \mathrm{~N} R), 2.79-2.72(\mathrm{~m}, 1 \mathrm{H}, \mathrm{H}-1 \mathrm{X} R), 2.62-2.47(\mathrm{~m}, 5 \mathrm{H}, \mathrm{H}-1 \mathrm{~N} S, \mathrm{H}-4 \mathrm{~N} S, \mathrm{H}-4 \mathrm{~N} R, \mathrm{H}-1 \mathrm{XS}$ and $\mathrm{H}-$ $4 \mathrm{XS}$ ), $2.47-2.40$ (m, 1H, H-4XR), 2.02 (ddd, $J=13.8 \mathrm{~Hz}, J=8.6 \mathrm{~Hz}, J=2.4 \mathrm{~Hz}, 1 \mathrm{H}, \mathrm{H}-3 \times \mathrm{XNS}$ ), 1.94-1.64 (m, 4H, H-3xNR, H-3nXR, H-3nXS and $\left.\mathrm{H}-7 \mathrm{aXX} R^{*}\right), 1.55-1.04(\mathrm{~m}, 16 \mathrm{H}, \mathrm{H}-3 \mathrm{nN} S, \mathrm{H}-$ $3 \times \mathrm{XS}, \mathrm{H}-7 \mathrm{~N}, \mathrm{H}-7 \mathrm{bXR} R^{* *}, \mathrm{H}-7 \mathrm{aXS} * \mathrm{H}-8 \mathrm{~N}$ and $\left.\mathrm{H}-8 \mathrm{X}\right), 0.99-0.81$ (m, 3H, H-3nNR, H-3xXR and H-7bXS**). ${ }^{13} \mathrm{C}$ NMR (75 MHz; $\left.\mathrm{CDCl}_{3}\right) \delta: 173.5$ (C, C-9X), 173.4 (C, C-9X), $173.2(\mathrm{C}, \mathrm{C}-9 \mathrm{~N})$, 173.1 (C, C-9N), 138.5 (C, ArX), 138.4 (2 C, ArX and ArN), 138.2 (C, ArN), 136.3 (CH, C-5X), 136.2 (CH, C-5X), 135.2 (CH, C-5N), 134.9 (CH, C-5N), 130.6 (CH, C-6X), 130.5 (CH, C-6X), $129.5(\mathrm{CH}, \mathrm{C}-6 \mathrm{~N} R), 129.4(\mathrm{CH}, \mathrm{C}-6 \mathrm{~N} S), 128.3,128.3,128.2,128.2,128.1,128.1$ and $128.0(12$ $\mathrm{CH}, \mathrm{Ar}), 126.3,126.2$ and $126.1(8 \mathrm{CH}, \mathrm{Ar}), 75.4(\mathrm{CH}, \mathrm{C}-2 \mathrm{~N}), 75.3(\mathrm{CH}, \mathrm{C}-2 \mathrm{~N}), 74.2(\mathrm{CH}, \mathrm{C}-$ 2X), $74.2(\mathrm{CH}, \mathrm{C}-2 \mathrm{X}), 72.8(\mathrm{CH}, \mathrm{C}-10 \mathrm{X}), 72.7(\mathrm{CH}, \mathrm{C}-10 \mathrm{X}), 72.6(\mathrm{CH}, \mathrm{C}-10 \mathrm{~N}), 72.5(\mathrm{CH}, \mathrm{C}-$ $10 \mathrm{~N}), 35.3\left(\mathrm{CH}_{2}, \mathrm{C}-3 \mathrm{~N}\right), 35.2\left(\mathrm{CH}_{2}, \mathrm{C}-3 \mathrm{~N}\right), 33.8(\mathrm{CH}, \mathrm{C} 1 \mathrm{X}), 33.7(\mathrm{CH}, \mathrm{C}-1 \mathrm{~N}), 33.6(\mathrm{CH}, \mathrm{C}-$ 1X), $33.5(\mathrm{CH}, \mathrm{C}-1 \mathrm{~N}), 33.0\left(\mathrm{CH}_{2}, \mathrm{C}-3 \mathrm{X}\right), 32.8\left(\mathrm{CH}_{2}, \mathrm{C}-3 \mathrm{X}\right), 29.3(\mathrm{CH}, \mathrm{C}-4 \mathrm{~N}), 29.3(2 \mathrm{CH}, \mathrm{C}-$ $4 \mathrm{~N}$ and $\mathrm{C}-4 \mathrm{X}), 29.2(\mathrm{CH}, \mathrm{C}-4 \mathrm{X}), 24.9\left(\mathrm{CH}_{2}, \mathrm{C}-8 \mathrm{X}\right), 24.7\left(\mathrm{CH}_{2}, \mathrm{C}-8 \mathrm{X}\right), 23.4\left(2 \mathrm{CH}_{2}, \mathrm{C}-8 \mathrm{~N}\right), 21.5$ $\left(\mathrm{CH}_{2}, \mathrm{C}-7 \mathrm{~N}\right), 21.3\left(\mathrm{CH}_{2}, \mathrm{C}-7 \mathrm{~N}\right), 18.2\left(\mathrm{CH}_{2}, \mathrm{C}-7 \mathrm{X}\right), 17.7\left(\mathrm{CH}_{2}, \mathrm{C}-7 \mathrm{X}\right)$. HRMS calcd for $\mathrm{C}_{16} \mathrm{H}_{22} \mathrm{NO}_{3}\left(\mathrm{M}+\mathrm{NH}_{4}\right)^{+}: 276.1594$, found: 276.1599 . 
$\boldsymbol{O}$-Acetylmandelates (8). To a solution of racemic 2,5-diphenyl-cyclohex-3-en-1-ol (endo/exo 47:53) $(69 \mathrm{mg}, 0.28 \mathrm{mmol})$ in dry DCM $(2.9 \mathrm{~mL})$, DMAP $(6.7 \mathrm{mg}, 0.06 \mathrm{mmol}),(S)-O-$ acetylmandelic acid $(107 \mathrm{mg}, 0.55 \mathrm{mmol})$ and DCC (114 mg, $0.55 \mathrm{mmol})$ were added and the mixture was stirred at room temperature for 60 minutes under argon. The reaction was diluted with DCM and filtered through Celite. The filtrate was concentrated under reduced pressure and purified by column chromatography (hexane/ethyl acetate) to afford a mixture of $O$ acetylmandelates 8 as a colorless oil (117.4 mg, 100\%, endo/exo 47:53, 8NR/8NS 50:50 and 8XR/8XS 50:50). IR (film) $v_{\max }$ : 3061, 3028, 2955, 2870, 1743, 1494, 1453, 1372, 1232, 1177 , $1055,700 \mathrm{~cm}^{-1} .{ }^{1} \mathrm{H}$ NMR $\left(300 \mathrm{MHz} ; \mathrm{CDCl}_{3}\right) \delta: 7.54-7.06(\mathrm{~m}, 58 \mathrm{H}, \mathrm{ArH}), 6.94-6.89(\mathrm{~m}, 2 \mathrm{H}$, ArH), 6.03-5.66 (m, 12H, H-3N, H-3X, H-4N, H-4X, H-8N and H-8X), 5.46-5.26 (m, 2H, H$1 \mathrm{~N})$, 5.15-5.05 (m, 2H, H-1X), 3.99-3.91 (m, 1H, H-2NR), 3.76-3.56 (m, 5H, H-2NS, H-2XR, H$5 \mathrm{~N} R, \mathrm{H}-5 \mathrm{~N} S$ and $\mathrm{H}-5 \mathrm{XS}), 3.46-3.39$ (m, 1H, H-2XS), 3.19-3.08 (m, 1H, H-5XR), 2.21 (s, 3H, H10X), 2.18 (s, 3H, H-10X), 2.09 (s, 3H, H-10N), 2.07 (s, 3H, H-10N), 2.15-1.98 (m, 2H, H-6N and H-6X), 1.92-1.58 (m, 6H, H-6N and H-6X). ${ }^{13} \mathrm{C}$ NMR (75 MHz; $\left.\mathrm{CDCl}_{3}\right) \delta$ : $170.1(2 \mathrm{C}, \mathrm{C}-$ 9X), 170.0 (2 C, C-9N), 168.2 (2 C, C-7N), 168.1 (2 C, C-7X), 144.4 (C, Ar), 144.3 (C, Ar), 144.0 (2 C, Ar), 140.6 (2 C, Ar), 137.9 (C, Ar), 137.6 (C, Ar), 134.0 (C, Ar), 133.6 (C, Ar), $133.5(\mathrm{C}, \mathrm{Ar}), 133.5$ (C, Ar), $131.7(\mathrm{CH}, 2 \mathrm{C}, \mathrm{C}-3 \mathrm{X}), 131.6(\mathrm{CH}, \mathrm{C}-3 \mathrm{~N}), 131.1(\mathrm{CH}, \mathrm{C}-3 \mathrm{~N})$, 130.4, 130.1, 129.1, 129.0, 128.9, 128.7, 128.7, 128.6, 128.5, 128.5, 128.4, 128.3, 127.8, 127.7, $127.5,127.5,127.3,127.2,127.0,126.8,126.7,126.6,126.5,126.5,126.4,126.3$ and $126.0(60$ $\mathrm{CH}, \mathrm{Ar}), 127.6(\mathrm{CH}, \mathrm{C}-4), 127.1(\mathrm{CH}, \mathrm{C}-4), 127.1(\mathrm{CH}, \mathrm{C}-4), 126.8(\mathrm{CH}, \mathrm{C}-4), 75.3(\mathrm{CH}, \mathrm{C}-$ 1X), $75.2(\mathrm{CH}, \mathrm{C}-1 \mathrm{X}), 74.5(\mathrm{CH}, \mathrm{C}-8), 74.4(2 \mathrm{CH}, \mathrm{C}-8), 74.3(\mathrm{CH}, \mathrm{C}-8), 73.2(\mathrm{CH}, \mathrm{C}-1 \mathrm{~N}), 73.1$ $(\mathrm{CH}, \mathrm{C}-1 \mathrm{~N}), 45.3(\mathrm{CH}, \mathrm{C}-2 \mathrm{XS}), 45.0(\mathrm{CH}, \mathrm{C}-2 \mathrm{XR}), 43.6(\mathrm{CH}, \mathrm{C}-2 \mathrm{~N} R), 43.5(\mathrm{CH}, \mathrm{C}-2 \mathrm{NS}), 42.7$ $(\mathrm{CH}, \mathrm{C}-5 \mathrm{~N}), 42.5(\mathrm{CH}, \mathrm{C}-5 \mathrm{~N}), 38.4(\mathrm{CH}, \mathrm{C}-5 \mathrm{XS}), 37.7(\mathrm{CH}, \mathrm{C}-5 \mathrm{XR}), 32.2\left(\mathrm{CH}_{2}, \mathrm{C}-6\right), 31.8$ $\left(\mathrm{CH}_{2}, \mathrm{C}-6\right), 31.7\left(\mathrm{CH}_{2}, \mathrm{C}-6\right), 30.9\left(\mathrm{CH}_{2}, \mathrm{C}-6\right), 20.6\left(\mathrm{CH}_{3}, \mathrm{C}-10\right), 20.5\left(2 \mathrm{CH}_{3}, \mathrm{C}-10\right), 20.4\left(\mathrm{CH}_{3}\right.$, C-10). HRMS calcd for $\mathrm{C}_{28} \mathrm{H}_{30} \mathrm{NO}_{4}\left(\mathrm{M}+\mathrm{NH}_{4}\right)^{+}: 444.2169$, found: 444.2169 .

$\boldsymbol{O}$-Acetylmandelates (10). To a solution of racemic 3- and 4-methyl-3-cyclohexen-1-ol (meta/para 34:66) (42 mg, $0.375 \mathrm{mmol})$ in dry DCM $(4.0 \mathrm{~mL})$, DMAP $(9.2 \mathrm{mg}, 0.08 \mathrm{mmol}),(S)$ $O$-acetylmandelic acid $(145 \mathrm{mg}, 0.750 \mathrm{mmol})$ and DCC $(155 \mathrm{mg}, 0.750 \mathrm{mmol})$ were added and the mixture was stirred at room temperature for 15 minutes under argon. The reaction was diluted with DCM and filtered through Celite. The filtrate was concentrated under reduced pressure and purified by column chromatography (hexane/ethyl acetate) to afford a mixture of $O$ acetylmandelates $\mathbf{1 0}$ as a colorless oil $(100.7 \mathrm{mg}, 93 \%$, meta/para 34:66, 10MR/10MS 50:50 and 10PR/10PS 50:50). IR (film) $v_{\max }$ : 3065, 3034, 2961, 2924, 2849, 1746, 1497, 1454, 1371, 1273 , 1233, 1179, 1082, 1053, 1004, 930, 847, 802, 737, $696 \mathrm{~cm}^{-1} .{ }^{1} \mathrm{H}$ NMR $\left(300 \mathrm{MHz} ; \mathrm{CDCl}_{3}\right) \delta$ : 7.52-7.30 (m, 20H, ArH), 5.92-5.85 (m, 4H, H-9P and H-9M), 5.38-5.29 (m, 2H, H-4M), 5.285.20 (m, 1H, H-3PR), 5.20-5.12 (m, 1H, H-3PS), 5.12-4.95 (m, 4H, H-1P and H-1M), 2.41-1.98 (m, 12H, H-6P, H-2M, H-2PR and H-6MS), 2.18 (br s, 12H, H-11M and H-11P), 1.98-1.46 (m, 12H, H-5P, H-2PS, H-5M and H-6MR), 1.63 (br s, 6H, H-7MR* and H-7P $R^{\dagger}$ ), 1.60 (br s, 3H, H$\left.7 \mathrm{PS} S^{\dagger}\right), 1.55$ (br s, 3H, H-7MS $\left.S^{*}\right) .{ }^{13} \mathrm{C}$ NMR $\left(75 \mathrm{MHz} ; \mathrm{CDCl}_{3}\right) \delta: 170.1$ (2 C, C-10P), 170.1 (2 C, C-10M), 168.3 (2 C, C-8M), 168.2 (2 C, C-8P), 133.9 (C, Ar), 133.8 (C, Ar), 133.7 (2 C, Ar), 
133.6 (C, C-4PS), 133.5 (C, C-4PR), 130.4 (C, C-3MS), 130.3 (C, C-3MR), 128.8, 128.5, 127.3, 127.2 (20 CH, Ar), 120.3 (CH, C-4M), 120.3 (CH, C-4M), $117.1(\mathrm{CH}, \mathrm{C}-3 \mathrm{P}), 117.1$ (CH, C-3P), 74.6 (2 CH, C-9P), 74.5 (2 CH, C-9M), 71.5 (2 CH, C-1M), $71.1(\mathrm{CH}, \mathrm{C}-1 \mathrm{PS}), 71.0(\mathrm{CH}, \mathrm{C}-$ $1 \mathrm{PR}), 34.9\left(\mathrm{CH}_{2}, \mathrm{C}-2 \mathrm{MS}\right), 34.6\left(\mathrm{CH}_{2}, \mathrm{C}-2 \mathrm{MR}\right), 30.2\left(\mathrm{CH}_{2}, \mathrm{C}-6 \mathrm{PS}\right), 30.0\left(\mathrm{CH}_{2}, \mathrm{C}-6 \mathrm{P} R\right), 27.4$ $\left(\mathrm{CH}_{2}, \mathrm{C}-2 \mathrm{PR}\right), 27.0$ (2 $\left.\mathrm{CH}_{2}, \mathrm{C}-5 \mathrm{P}\right), 26.6\left(\mathrm{CH}_{2}, \mathrm{C}-2 \mathrm{PS}\right), 26.4\left(\mathrm{CH}_{2}, \mathrm{C}-5 \mathrm{M}\right), 26.2\left(\mathrm{CH}_{2}, \mathrm{C}-5 \mathrm{M}\right)$, $23.1\left(\mathrm{CH}_{3}, \mathrm{C}-7 \mathrm{M}\right), 23.0\left(3 \mathrm{CH}_{3}, \mathrm{C}-7 \mathrm{P}\right.$ and $\left.\mathrm{C}-7 \mathrm{M}\right), 22.5\left(\mathrm{CH}_{2}, \mathrm{C}-6 \mathrm{M}\right), 22.2\left(\mathrm{CH}_{2}, \mathrm{C}-6 \mathrm{M}\right), 20.5(4$ $\mathrm{CH}_{3}, \mathrm{C}-11 \mathrm{P}$ and $\left.\mathrm{C}-11 \mathrm{M}\right)$. HRMS calcd for $\mathrm{C}_{17} \mathrm{H}_{21} \mathrm{O}_{4}(\mathrm{M}+\mathrm{H})^{+}:$289.1434, found: 289.1442 .

\section{Supplementary Material}

NMR spectra for all new compounds and optimized geometries of contributing conformers for all compounds.

\section{Acknowledgements}

We thank CONICET, Universidad Nacional de Rosario and ANPCyT for financial support. P. L. P. thanks ANPCyT and CONICET for the awards of fellowships. A. M. S. thanks CONICET for the award of a fellowship.

\section{References and Notes}

1. Seco, J. M.; Quiñoá, E.; Riguera, R. Chem. Rev. 2004, 104, 17.

2. (a) Dale, J. A.; Mosher, H. S. J. Am. Chem. Soc. 1973, 95, 512. (b) Whitesell, J. K.; Reynolds, D. J. Org. Chem. 1983, 48, 3548. (c) Trost, B. M.; Belletire, J. L.; Godleski, S.; McDougal, P. G.; Balkovec, J. M.; Baldwin, J. J.; Christy, M. E.; Ponticello, G. S.; Varga, S. L. Springer, J. P. J. Org. Chem. 1986, 51, 2370. (d) Chataigner, I.; Lebreton, J.; Durand, D.; Guingant, A.; Villiéras, J. Tetrahedron Lett. 1998, 39, 1759. (e) Sureshan, K. M.; Miyasou, T.; Hayashi, M.; Watanabe Y. Tetrahedron: Asymmetry 2004, 15, 3. (f) Sureshan, K. M.; Miyasou, T. Miyamori, S.; Watanabe, Y. Tetrahedron: Asymmetry 2004, 15, 3357.

3. Pisano, P. L.; Pellegrinet, S. C. XXVIII Argentine Congress of Chemistry and 4th Workshop of Medicinal Chemistry, Lanús, Argentina - September 13 -16, 2010: Abstract No. 066.

4. Pisano, P. L.; Sarotti, A. M.; Pellegrinet, S. C. Tetrahedron Lett. 2009, 50, 6121.

5. The cyclohexenols used in this study were obtained as racemic mixtures by Diels-Alder reactions of pinacol vinylboronate and the corresponding dienes (1,3-cyclohexadiene for 4, trans,trans-1,4-diphenyl-1,3-butadiene for 7 and isoprene for 9). Sarotti, A. M.; Pisano, P. L.; Pellegrinet, S. C. Org. Biomol. Chem. 2010, 8, 5069. 
6. Saravanan, P.; Bisai, A.; Baktharaman, S.; Chandrasekhar, M.; Singh, V. K. Tetrahedron 2002, 58, 4693.

7. We have named the studied derivatives as follows: the letters $\mathrm{N}$ and $\mathrm{X}$ denote endo and exo stereochemistry (compounds 5, 6 and $\mathbf{8}$ ) and $\mathrm{M}$ and $\mathrm{P}$ indicate meta and para regiochemistry (compound 10) whereas $R$ and $S$ describe the absolute confirguration of the carbinolic center.

8. Hyperchem Professional Release 7.52, Hypercube, Inc., 2005.

9. Frisch, M. J.; Trucks, G. W.; Schlegel, H. B.; Scuseria, G. E.; Robb, M. A.; Cheeseman, J. R.; Montgomery, J. A., Jr., Vreven, T.; Kudin, K. N.; Burant, J. C.; Millam, J. M.; Iyengar, S. S.; Tomasi, J.; Barone, V.; Mennucci, B.; Cossi, M.; Scalmani, G.; Rega, N.; Petersson, G. A.; Nakatsuji, H.; Hada, M.; Ehara, M.; Toyota, K.; Fukuda, R.; Hasegawa, J.; Ishida, M.; Nakajima, T.; Honda, Y. Kitao, O.; Nakai, H.; Klene, M.; Li, X.; Knox, J. E.; Hratchian, H. P.; Cross, J. B.; Adamo, C.; Jaramillo, J.; Gomperts, R.; Stratmann, R. E.; Yazyev, O.; Austin, A. J.; Cammi, R.; Pomelli, C.; Ochterski, J. W.; Ayala, P. Y.; Morokuma, K.; Voth, G. A.; Salvador, P.; Dannenberg, J. J.; Zakrzewski, V. G.; Dapprich, S.; Daniels, A. D.; Strain, M. C.; Farkas, O.; Malick, D. K.; Rabuck, A. D.; Raghavachari, K.; Foresman, J. B.; Ortiz, J. V.; Cui, Q.; Baboul, A. G.; Clifford, S.; Cioslowski, J.; Stefanov, B. B.; Liu, G.; Liashenko, A.; Piskorz, P.; Komaromi, I.; Martin, R. L.; Fox, D. J.; Keith, T.; Al-Laham, M. A.; Peng, C. Y.; Nanayakkara, A.; Challacombe, M.; Gill, P. M. W.; Johnson, B.; Chen, W.; Wong, M. W.; Gonzalez, C.; Pople, J. A. Gaussian 03, Revision C.02, Gaussian, Inc., Wallingford CT, 2004.

10. Bifulco, G.; Dambruoso, P.; Gomez-Paloma, L.; Riccio, R. Chem. Rev. 2007, 107, 3744.

11. Ammazzalorso, A.; Bettoni, G.; De Filippis, B.; Fantacuzzi, M.; Giampietro, L.; Giancristofaro, A.; Maccallini, C.; Re, N.; Amoroso, R., Coletti, C. Tetrahedron Asymmetry 2008, 19, 989.

12. The chemical shifts of the signals of the protons that lie within complex multiplets were estimated from COSYHH and HSQC spectra.

13. The phenyl groups on $\mathrm{C}-5$ and $\mathrm{C}-2$ adopt pseudo-equatorial and pseudo-axial positions in all structures. Nevertheless, the half-chair conformation of the cyclohexene ring seems to be slightly distorted due to the presence of the two cis phenyl groups, as suggested by the corresponding torsion angles, probably to minimize the steric clashes between the aromatic rings. 